\title{
Challenges and Opportunities for Improving Food Quality and Nutrition Through Plant Biotechnology
}

\author{
David Francis $^{\mathrm{a}, \mathrm{b}}$, John J. Finer ${ }^{\mathrm{a}, \mathrm{b}}$ and Erich Grotewold ${ }^{\mathrm{a}, \mathrm{c}, \mathrm{d}, \mathrm{e}}$
}

${ }^{\mathrm{a}}$ Department of Horticulture and Crop Science, ${ }^{\mathrm{b}}$ Ohio Agricultural Research and Development Center, The Ohio State University, Wooster, OH 44961. 'Department of Molecular Genetics, ${ }^{\mathrm{d}}$ Center for Applied Plant Sciences, The Ohio State University, Columbus, 43210.

${ }^{\mathrm{e}}$ Corresponding Author:

Erich Grotewold

206 Rightmire Hall, 1060 Carmack Road

Center for Applied Plant Sciences

The Ohio State University

Columbus, $\mathrm{OH} 43210$

E-mail: grotewold.1@osu.edu 


$\begin{array}{ll}\text { Abbreviations } \\ \text { Bt } & \text { Bacillus thuringiensis toxin } \\ \text { Cas9 } & \text { CRISPR Associated Protein9 } \\ \text { CRISPR } & \text { Clustered Regularly Interspaced Short Palindromic Repeat } \\ \text { GMO } & \text { Genetically Modified Organism } \\ \text { TALENs } & \text { Transcription Activator-Like Effector Nucleases } \\ \text { TMV } & \text { Tobacco Mosaic Virus } \\ \text { USDA } & \text { United States Department of Agriculture } \\ \text { ZFN } & \text { Zinc-Finger Nucleases }\end{array}$

\section{KEY WORDS}

Breeding, domestication, natural variation, transgenic, 
Plant biotechnology has been around since the advent of humankind, resulting in tremendous improvements in plant cultivation through crop domestication, breeding and selection. The emergence of transgenic approaches involving the introduction of defined DNA sequences into plants by humans has rapidly changed the surface of our planet by further expanding the gene pool used by plant breeders for plant improvement. Transgenic approaches in food plants have raised concerns on the merits, social implications, ecological risks and true benefits of plant biotechnology. The recently acquired ability to precisely edit plant genomes by modifying native genes without introducing new genetic material offers new opportunities to rapidly exploit natural variation, create new variation and incorporate changes with the goal to generate more productive and nutritious plants. 


\section{Introduction}

Agricultural output derived from the development of high-yield varieties of grains combined with technological improvements resulted in food production continuously expanding since the 1960s [1]. As a consequence, caloric intake is often not limiting in diets while phytonutrient deficiencies continue to be prevalent [2]. This situation results in a "double burden" in which the persistence of malnutrition in specific sectors of the population, particularly children, coexists with an increase in obesity and diet-related chronic diseases, such as diabetes. There is therefore strong interest in developing a new generation of enhanced crops that can address diet-related chronic diseases.

\section{GLOSSARY}

Biotechnology - Discipline in which biological processes, organisms or its components are harnessed for the benefit of humankind.

Genetically Modified Organism (GMO) - Organism resulting from the introduction of single or multiple transgene(s).

Genetic Diversity - Genetic diversity refers to both the number of different species as well as the diversity within a species. Genetic diversity is quantified relative to the number of different alleles and their frequency in populations.

Natural Variation - Genetic diversity at the phenotypic or DNA level which occurs within a plant species in the wild.

Transgene - An isolated gene, originally introduced into a target cell, using biological or physical vectors.

Plant Transformation - The process of transgene introduction into plants.
Malnutrition is indeed a complex problem caused by policy, production, distribution and marketing in the food system which has a major impact on health and the economics of the regions affected [3]. Improving the phytonutrient content of crops, referred to as biofortification, has been promoted as one potential solution [4]. Increasing food security through incorporation of underutilized and neglected crops into food production as a way to address local challenges imposed by changing climate and/or pathogens is another strategy that may compliment

biofortification [5]. From the 7,000 or so plant species that humans have cultivated for food, about 30 crops provide $95 \%$ of the food energy needs, with four of them (rice, wheat, maize and potato) responsible for about 60\% (http://www.fao.org/biodiversity/components/plants/en/). By diversifying crops, risk is minimized and delivery of biofortified crops may be tailored to local food systems. Plant biotechnology is clearly one piece in the solution space, but will need to be accompanied by significant changes in the ways food is transported and processed to minimize waste and ensure that it reaches the neediest in an affordable way [6]. Technological solutions also require that new methods be embraced and adopted by governments, the public and farmers [7].

This review focuses primarily on how plant biotechnology provides opportunities to address several of the challenges associated with the need for high quality and sufficient food as the world population grows. Not surprisingly, much of the research has focused on crops with the largest production output (e.g., maize, soybean, and rice), but there are several significant accomplishments that have been made in other food plants (e.g., papaya and potato) that highlight the broad reach and large impact of plant biotechnology.

\section{The multiple flavors of plant biotechnology}


Plant biotechnology in the broad sense has been going on since the dawn of civilization, when founder crops started being cultivated in Levant (Figure 1). Crop domestication followed, starting around 13,000 years ago, significantly impacting the morphology and genomes of the plants involved [8,9]. Domestication is indeed one of the most dramatic examples of biotechnology, resulting in the transformation of wild plants into ones with accessible and abundant fruits and grains, while retaining traits that allowed the wild plant to succeed in the first place. Selective breeding followed domestication, permitting agriculturalists to choose for and combine specific traits found within primary gene pools (Figure 2). Today, there is renewed interest in conserving wild relatives as technology permits us to more efficiently harness the genetic diversity in secondary gene pools to enhance crops $[10,11]$. It was only in the past 50 years that techniques became available that permitted the incorporation into plants of genes from other species through transformation. The last couple of decades have witnessed the development of many tools that permit the specific editing of the genome, providing an opportunity to rapidly incorporate new traits and genes into elite cultivars [12].

\section{Plant Breeding}

Variation is the key ingredient in plant breeding. For this reason the science of crop improvement is focused first on the efficient discovery, creation and manipulation of genetic variation followed by selection. The methods used to identify, create, and introduce new variation have evolved with time (Figure 1). Traditional breeding combines variation from different sources through pollen transfer. This approach is responsible for much of the gain in crop genetic performance over the last one hundred years as exemplified by the increased yield associated with hybrid corn [13]. In this case, hybridization exploits heterosis or hybrid vigor, the phenomenon in which progeny perform better than both parents [14]. In traditional breeding, selection is based on observing combinations of traits, and selecting based on phenotype. This step is now aided by enhanced allele prediction and selection, known as genomic selection. This methodology is applied to segregating populations and is driven by abundant DNA sequence data highlighting nucleotide variation and predictive models that are feasible due to improved computational resources and open-source software $[15,16]$. Technology is also applied to access or create new sources of variation which may not be accessible through pollen transfer alone.

\section{Chromosome and Embryo Manipulation}

The ingredient list available for plant improvement can be expanded by technologies that help access new sources of variation when supplemented by chromosome and embryo manipulation. The creation of haploids followed by chromosome doubling to create "doubled haploids" is removing the need for inbreeding to create uniform lines, thus speeding the breeding process [17]. Common crops (e.g., strawberry, wheat) are the result of natural hybridization and chromosome doubling to create polyploids. Hybridization of grasses to produce wheat occurred over 10,000 years ago through natural pollen transfer [18]. More recently, interspecific hybridization has been facilitated through tissue culture techniques. As an example, tomato resistance to TMV was transferred from a wild species by embryo rescue and has protected the 
crop for over 40 years [19]. The pollen transfer of genes from wild relatives remains among the most viable solutions to emerging plant viruses which are vectored by insect pests [20].

\section{Transgenic technologies expand the ingredient pool}

Expanding the ingredient list to include genetic variation beyond that accessible through pollen transfer has been the promise of genetically modified organisms. As transgenic technologies allow for the movement of genes from any source into any target plant, tremendous opportunities exist to expand the genetic base of ingredients used for improvements to plant food quality and nutrition. Most of the commercially successful plants altered through biotechnology have been transgenic field crops, which account for greater than $90 \%$ of the soybean, $85 \%$ of the corn and $90 \%$ of cotton, grown in the USA [21]. These transgenic plants display new characteristics for herbicide and insect resistance with the majority of new genetic components from bacteria, viruses and other plants. Surprisingly, the first deregulated, commercialized product of plant biotechnology was a food crop, which failed. Flavr Savr tomatoes were engineered to contain an antisense version of a polygalacturonidase gene, which slowed ripening of the mature tomato fruit. Although the technology worked to prevent over-ripening, the product was never profitable, teaching the biotechnology community important lessons with regards to the need to integrate transgenic and breeding approaches with consumer acceptance and use.

Since transgenic approaches allow the inter-kingdom transfer of genes into plants (i.e., bring ingredients from the Gene Ocean; Figure 2), the gene pool can be expanded well beyond sexually compatible species, offering a wide and wild assortment of different ingredients to the adventurous plant breeder. Some of the transgenic food approved for non-regulated status include virus resistance squash, Bt potato, low acrylamide potato, virus resistant papaya, herbicide resistant flax, virus resistant plum and non-browning apple (www.aphis.usda.gov/biotechnology/). The virus resistant plum has not been commercialized because plum pox virus is not problematic in regions of California where most plums are grown in the USA, further underlining the need to integrate transgenic approaches with the existing infrastructure for food production and delivery.

\section{Genome editing as tool for designed variations}

Most recently, genome editing and genome engineering technologies offer the ability to create variation by modifying existing genes and target transgenes to specific sites in the genome, respectively [12]. In many ways, genome editing is a more precise variation of mutation breeding, which has been practiced to create new variation for nearly 100 years. Genome engineering makes use of the cell's DNA repair pathway and sequence-specific nucleases that can be custom-designed to target almost any DNA sequence in a plan genome (reviewed in [22]). The development and application for plant genome editing of ZFNs and TALENs has been extensively reviewed previously [12,22,23]. The most recent development in genome

engineering is the CRISPR system mediated by the bacterial nuclease Cas9 [24] The CRISPR/Cas9 system has a number of advantages that make it much more promising and less 
laborious than ZFNs and TALENs. In a nutshell, the CRISPR/Cas9 system consists of two components that need to be expressed in the same plant cell for the genome to be edited: The Cas9 nuclease and a guide RNA homologous to the sequence to be edited that guides the nuclease to the correct location in the genome (recently reviewed in $[25,26]$ ). The system permits mutations to be generated at a desired site, and with a lower frequency, to incorporate desired DNA fragments taking advantage of the double brakes introduced by Cas9 and the plant repair machinery. If the Cas9 and edited sites are unlinked, the gene for the Cas9 nuclease can be segregated out, essentially leaving no trace in the genome, besides the edited site. The debate continues both in society and at the regulatory level on whether CRISPR/Cas9 engineered plants are considered transgenic or not $[27,28]$. However, the USDA has already signaled that it will not regulate the common white button mushroom, which was engineered to resist browning through Cas9 modification of the polyphenol oxidase (PPO) pathway $[29,30]$.

\section{Improving Food Quality and Nutrition}

Plant breeding has been successful in using natural variation to create food crops that are improved for quality and nutritional characteristics. A walk through the produce section of any major grocery store will reveal a diversity of fruits and vegetables with pigments, nutrients, and flavor qualities that have been affected by natural variation and breeding. The range of colors found in tomato, as an example, are due to differences in the carotenoids which also have health benefits, providing protection from cancer, cardiovascular disease, osteoporosis, and other chronic diseases caused by oxidative stresses [31,32]. The variation in color patterns found in fruits and vegetables is due to natural variation in structural genes (enzymes) and regulatory components (transcription factors and cis-regulatory regions). The rich pigment patterns that distinguish "Indian corn" from common feed corn are due to another class of pigments, the anthocyanins, which are derived from flavonoids. There is an interest in re-introducing valuable flavonoids into maize seeds, taking advantage of the large natural variation available [33]. Sweet potato [Ipomoea batatas (L.) Lam.] provides an example of a biofortification project based on natural variation where children consuming the improved potatoes showed increased vitamin A levels [34]. The project was recognized by the 2016 World Food Prize for Fight Against Malnutrition, and its success was due in part to the integration of biological, nutritional, and social science with a competitive product.

But there are cases in which the natural variation available through pollen transfer is not sufficient, and it is necessary to access genes from a larger source, the Gene Ocean (Figure 2). "Golden rice" is among the more popular examples of such engineering, where rice endosperm was modified by the introduction of the $\beta$-carotene biosynthetic pathway [35]. Currently "Golden rice" remains a controversial dream as an example of a "humanitarian" GMO crop, as it has not yet reached commercialization. Insect resistant (Bt expressing) eggplant for South East Asia provides another example, one in which pesticide use can be decreased while allowing farmers to produce an important vegetable $[36,37]$. It should be noted that failure to commercialize in the case of "Golden rice", or failure in the commercial market as was the case of the Flavr Savr, may 
have nothing to do less with GMO opposition and more with a product that is not ready for market [38].

There are also examples where natural variation will compete with engineered variation. A good recent example is provided by the "Purple Tomatoes". Tomatoes normally accumulate low levels of anthocyanin pigments, but two regulatory proteins from snapdragon were introduced, and tomato fruits accumulating very high levels of health-promoting anthocyanin resulted [39]. These Purple Tomatoes are not only more nutritious, but have also extended shelf life and mold resistance [40]. At the same time, naturally occurring variation has accomplished a similar, though perhaps less dramatic phenotype [41], resulting in the commercialization of the "Indigo Rose" tomato. When technologies compete, it will often be the mundane practical decisions that determine which approach reaches the market first.

Clearly, biotechnology applied to plant improvement has permitted humankind to grow and move from a condition of overall caloric shortage, to a significantly better, albeit unevenly distributed, state of nourishment. The technologies and germplasm that resulted from the Green Revolution (from ' 30 s to late '60s) primarily benefitted developing countries by significantly increasing productivity. Are the more recent developments in plant biotechnology benefitting everybody equally? This question can be approached from two perspectives: from the beneficiaries' perspective and the consequences for better quality and more food availability, or from the plant scientist perspective in terms of what traits were selected or introduced into new or existing crops. Most of the first generation traits in transgenic plants corresponded to what we would call grower or input traits; traits such as increased resistance to pests or to herbicides that provide benefits to agricultural practice, but may not be directly beneficial to the consumer. Most of the next generation transgenics contain gene stacks, which carry both input traits but also quality or output traits, such as modified oil content, greater aesthetics and improved nutrition. Output traits are useful to the consumer, in addition to the farmer. Almost unlimited opportunities exist for the introduction of additional consumer traits (such as provided by Golden Rice, Figure 1), but regulatory issues, social concerns and economic interests have sidelined many of the potential products, which require energetic and accomplished advocates to push them through the commercialization process.

Efforts in the commercialization process have shifted from the actual generation of transgenic plants to addressing the regulatory issues, which have been put in place to show product safety and ease consumer concerns. Although the regulatory guidelines were initially established to prevent unforeseen consequences, they have morphed into a huge complex regulatory structural network, where transgenics must be shown to be "equivalent" to nontransgenics and the process of producing new plants is emphasized over the product [42]. The black and white days of commercial plant biotechnology products with high regulatory hurdles seem to be changing with the ability to introduce only plant-derived sequences and the advances in genome editing [43]. Plants produced using these processes are not subject to the control of most federal regulatory agencies [42]. It is not clear if the guidelines will again change or these 
and future products will continue to be exempt. As our abilities to change the genetic makeup of plants continue to improve, it is likely that new guidelines will direct those efforts.

\section{Conclusions}

Agriculture faces significant challenges in the light of climate change, emerging pests and pathogens, and a rapidly growing and wealthier population. We are at an exciting and revolutionary time for plant genetic improvement with new tools to meet these challenges. For most crops, reference genomes exist. In addition, there are thousands of non-crop genomes available, providing abundant opportunities to discover new allelic variation and facilitate genomic-based breeding. Biotechnology in the broad sense offers a powerful set of research tools to address basic questions in plant science related to food production. GMO technologies and genome editing provide opportunities to create new variation rapidly, and this variation has the ability to solve real world problems. Many of the products from basic research may also find a commercial home. Recent success stories in biofortification provide a template for future success. For the potential of biotechnology to be realized, research needs to consider a complex milieu of issues from regulation, intellectual property, cultural preferences, local conditions, and existing market standards.

\section{Acknowledgements}

The EG lab acknowledges the Agriculture and Food Research Initiative competitive grant 2015-67013-22810 of the USDA National Institute of Food and Agriculture for research on crop improvement. Salaries and research support were provided in part by State and Federal Funds appropriated to the Ohio Agricultural Research and Development Center, The Ohio State University. Mention of trademark or proprietary products does not constitute a guarantee or warranty of the product by OSU/OARDC and also does not imply approval to the exclusion of other products that may also be suitable.

\section{Figure Legends}

\section{Figure 1: Timeline of key events in plant biotechnology.}

Figure 2: The gene pool space for plant biotechnology. The $1^{\text {st }}$ Gene Pool corresponds to genetic variation exchanged through pollen fertilization with no barriers. The $2^{\text {nd }}$ Gene Pool to genetic variation exchanged through pollen fertilization with some sterility, distorted segregation. The $3^{\text {rd }}$ Gene Pool corresponds to genetic variation exchanged through pollen fertilization; chromosome manipulation or embryo rescue techniques required to retrieve viable progeny. The Gene Ocean corresponds to the genetic variation from all other organisms, which can only be accessed through transgenics. Adapted from [44].

\section{References}


1. Huang J, Pray C, Rozelle S: Enhancing the crops to feed the poor. Nature 2002, 418:678684.

2. Finn S: Nutrition insecurity and malnutrition in developed countries. In Addressing malnutrition to improve global health. Science 2014, 346:1247.

3. Philipson TJ, Linthicum MT, Thornton Snider J: The global economic burden of malnutrition. In Addressing malnutrition to improve global health. Science 2014, 346:1247.

*This article in a Sponsored Supplement to Science highlights cost-effective solutions aimed at reducing malnutrition that is not limited to developing countries, and which affects different sectors of the population in developing and developed countries.

4. Hefferon KL: Nutritionally enhanced food crops; progress and perspectives. Int. J Mol Sci 2015, 16:3895-3914.

5. Mayes S, Massawe FJ, Alderson PG, Roberts JA, Azam-Ali SN, Hermann M: The potential for underutilized crops to improve security of food production. $J$ Exp Bot 2012, 63:1075-1079.

6. Gilligan DO: Biofortification, agricultural technology adoption, and nutrition policy: Some lessons and emerging challenges. CES Econ Stud 2012, 58:405-421.

7. Malyska A, Bolla R, Twardowski T: The role of public opinion in shaping trajectories of agricultural biotechnology. Trends Biotechnol 2016, 34:530-534.

8. Meyer RS, DuVal AE, Jensen HR: Patterns and processes in crop domestication: An historical review and quantitative analysis of $\mathbf{2 0 3}$ global food crops. New Phytol 2012, 196:29-48.

9. Cheng F, Sun R, Hou X, Zheng H, Zhang F, Zhang Y, Liu B, Liang J, Zhuang M, Liu Y, et al.: Subgenome parallel selection is associated with morphotype diversification and convergent crop domestication in Brassica rapa and Brassica oleracea. Nat Genet 2016, advance online publication.

**This study highlights the important role of poly-plodization on the convergence of many domestication traits associated with modern cabagge, turnip and kohlrabi, and the diversification into heading or tuber-forming varieties. The study highlights the importance of having genome sequence information for many accessions and natural variants to reconstruct domestication history.

10. Gruber K: Re-igniting the green revolution with wild crops. Nature Plants 2016, 2:16048.

11. Castañeda-Álvarez NP, Khoury CK, Achicanoy HA, Bernau V, Dempewolf H, Eastwood RJ, Guarino L, Harker RH, Jarvis A, Maxted N, et al.: Global conservation priorities for crop wild relatives. Nat Plants 2016, 2:16022.

12. Baltes NJ, Voytas DF: Enabling plant synthetic biology through genome engineering. Trends Biotechnol 2015, 33:120-131.

13. Crow JF: 90 years ago: The beginning of hybrid maize. Genetics 1998, 148:923.

14. Fridman E: Consequences of hybridization and heterozygosity on plant vigor and phenotypic stability. Plant Science 2015, 232:35-40.

15. Abberton M, Batley J, Bentley A, Bryant J, Cai H, Cockram J, Costa de Oliveira A, Cseke LJ, Dempewolf H, De Pace C, et al.: Global agricultural intensification during climate change: A role for genomics. Plant Biotechnol J 2016, 14:1095-1098.

16. Mondal S, Rutkoski JE, Velu G, Singh PK, Crespo-Herrera LA, Guzman C, Bhavani S, Lan $\mathrm{C}$, He X, Singh RP: Harnessing diversity in wheat to enhance grain yield, climate 
resilience, disease and insect pest resistance and nutrition through conventional and modern breeding approaches. Front Plant Sci 2016, 7:991.

17. Prigge V, Melchinger AE: Production of haploids and doubled haploids in maize. Methods Mol Biol 2012, 877:161-172.

18. Gegas VC, Nazari A, Griffiths S, Simmonds J, Fish L, Orford S, Sayers L, Doonan JH, Snape JW: A genetic framework for grain size and shape variation in wheat. Plant Cell 2010, 22:1046-1056.

19. Alexander LJ: Transfer of a dominant type of resistance to the four known Ohio pathogenic strains of Tobacco Mosaic Virus (TMV), from Lycopersicon peruvianum to L. esculentum. Phytopathology 1963, 53:896.

20. Caro M, Verlaan MG, Julián O, Finkers R, Wolters A-MA, Hutton SF, Scott JW, Kormelink R, Visser RGF, Díez MJ, et al.: Assessing the genetic variation of $T y-1$ and $T y-3$ alleles conferring resistance to Tomato Yellow Leaf Curl Virus in a broad tomato germplasm. Mol Breed 2015, 35:132.

21. Fernandez-Cornejo J, Wechsler S, Livingston M, Mitchell L: Genetically engineered crops in the United States. U.S. Department of Agriculture; 2014.

22. Voytas DF: Plant genome engineering with sequence-specific nucleases. Ann Rev Plant Biol 2013, 64:327-350.

23. Voytas DF, Gao C: Precision genome engineering and agriculture: Opportunities and regulatory challenges. PLoS Biol 2014, 12:e1001877.

24. Belhaj K, Chaparro-Garcia A, Kamoun S, Patron NJ, Nekrasov V: Editing plant genomes with crispr/cas9. Curr Opin Biotechnol 2015, 32:76-84.

25. Bortesi L, Fischer R: The crispr/cas9 system for plant genome editing and beyond. Biotech Adv 2015, 33:41-52.

26. Ma X, Zhu Q, Chen Y, Liu Y-G: CRISPR/CAS9 platforms for genome editing in plants: Developments and applications. Mol Plant 2016, 9:961-974.

27. Wolt JD, Wang K, Yang B: The regulatory status of genome-edited crops. Plant Biotech J 2016, 14:510-518.

28. Araki M, Ishii T: Towards social acceptance of plant breeding by genome editing. Trends Plant Sci 2015, 20:145-149.

29. Waltz E: Gene-edited CRISPR mushroom escapes US regulation. Nature 2016, 532:293.

30. Hall SS: Editing the mushroom. Sci Am 2016, 314:56-63.

31. Perveen R, Suleria HAR, Anjum FM, Butt MS, Pasha I, Ahmad S: Tomato (Solanum lycopersicum) carotenoids and lycopenes chemistry; metabolism, absorption, nutrition, and allied health claims-a comprehensive review. Crit Rev Food Sci and Nutr 2015, 55:919-929.

32. Calafiore R, Ruggieri V, Raiola A, Rigano MM, Sacco A, Hassan MI, Frusciante L, Barone A: Exploiting genomics resources to identify candidate genes underlying antioxidants content in tomato fruit. Front Plant Sci 2016, 7:397.

33. Casas MI, Duarte S, Doseff AI, Grotewold E: Flavone-rich maize: An opportunity to improve the nutritional value of an important commodity crop. Front Plant Sci 2014, 5:440.

34. Hotz C, Loechl C, Lubowa A, Tumwine JK, Ndeezi G, Nandutu Masawi A, Baingana R, Carriquiry A, de Brauw A, Meenakshi JV, et al.: Introduction of beta-carotene-rich orange sweet potato in rural Uganda resulted in increased vitamin a intakes among 
children and women and improved vitamin a status among children. $J$ Nutr 2012, 142: $1871-1880$.

**This article addresses Vitamin A deficiency in Uganda through consumption of $\beta$-carotenerich orange sweet potato. Natural variation in $\beta$-carotene content was exploited to develop enriched sweet potato, and introduction of these varieties to farming households in Uganda increased vitamin A intake and improved vitamin A status among children.

35. Ye X, Al-Babili S, Kloti A, Zhang J, Lucca P, Beyer P, Potrykus I: Engineering the provitamin a ( $\beta$-carotene) biosynthetic pathway into (carotenoid-free) rice endosperm. Science 2000, 287:303-305.

36. Gupta PK, Choudhary B, Gheysen G: Removing Bt eggplant from the face of Indian regulators. Nat Biotechnol 2015, 33:904-907.

37. Hautea DM, Taylo LD, Masanga AP, Sison ML, Narciso JO, Quilloy RB, Hautea RA, Shotkoski FA, Shelton AM: Field performance of Bt eggplants (Solanum melongena 1.) in the Philippines: Cry1Ac expression and control of the eggplant fruit and shoot borer (Leucinodes orbonalis guenee). PLoS One 2016, 11:e0157498.

38. Stone GD, Glover D: Disembedding grain: Golden rice, the green revolution, and heirloom seeds in the Philippines. Ag Human Values 2016:1-16.

39. Butelli E, Titta L, Giorgio M, Mock HP, Matros A, Peterek S, Schijlen EG, Hall RD, Bovy AG, Luo J, et al.: Enrichment of tomato fruit with health-promoting anthocyanins by expression of select transcription factors. Nat Biotechnol 2008, 26:1301-1308.

40. Zhang Y, Butelli E, De Stefano R, Schoonbeek HJ, Magusin A, Pagliarani C, Wellner N, Hill L, Orzaez D, Granell A, et al.: Anthocyanins double the shelf life of tomatoes by delaying overripening and reducing susceptibility to gray mold. Curr Biol 2013, 23:1094-1100.

41. Jones CM, Mes P, Myers JR: Characterization and inheritance of the anthocyanin fruit (Aft) tomato. J Hered 2003, 94:449-456.

42. Wolt JD, Yang B, Wang K, Spalding MH: Regulatory aspects of genome-edited crops. In Vitro Cell Dev Biol Plant 2016:1-5.

*This review article provides a short and balanced analysis of the process versus product conundrum under current regulatory guidelines for plants modified via genome editing.

43. Gray DJ, Li ZT, Dhekney SA: Precision breeding of grapevine (Vitis vinifera l.) for improved traits. Plant Science 2014, 228:3-10.

*In this article, the authors argue that transgenic grape that contain re-introduced native or slightly modified native DNA sequences be rebranded as products of "precision breeding". These types of products have classically been known as "cisgenics" or intragenics" and fall under different regulatory oversight than classically produced transgenic crop plants.

44. Harlan JR, de Wet JMJ: Toward a rational classification of cultivated plants. Taxon 1971, 20:509-517. 


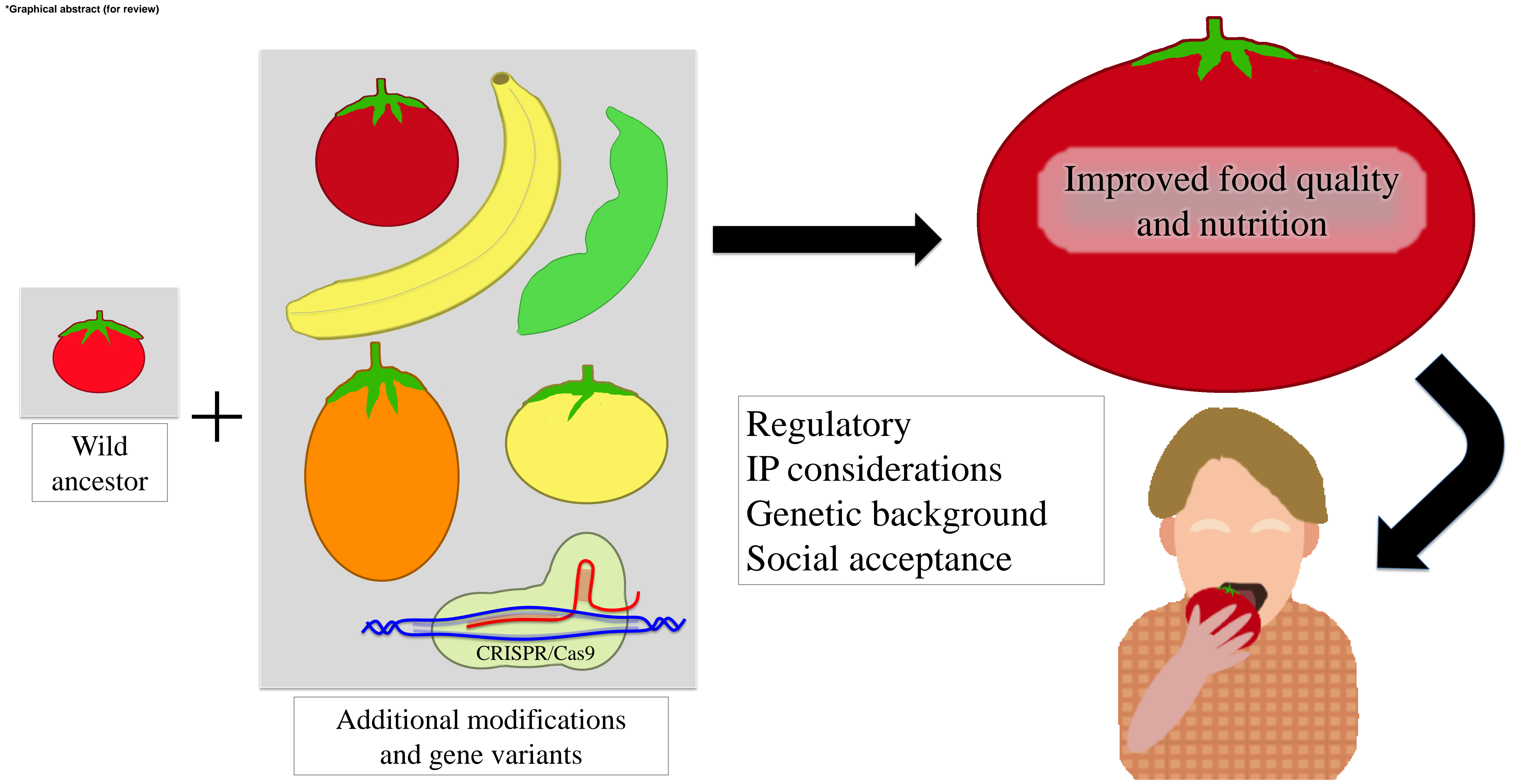



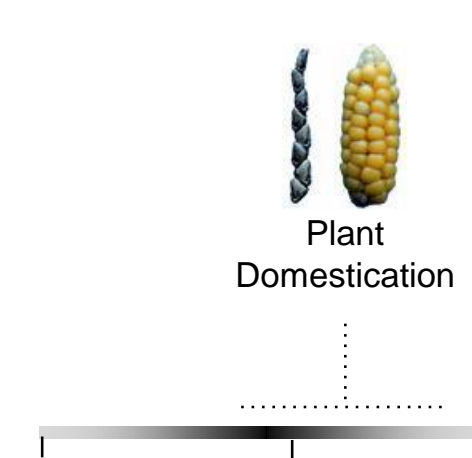

ca. 8000 BC

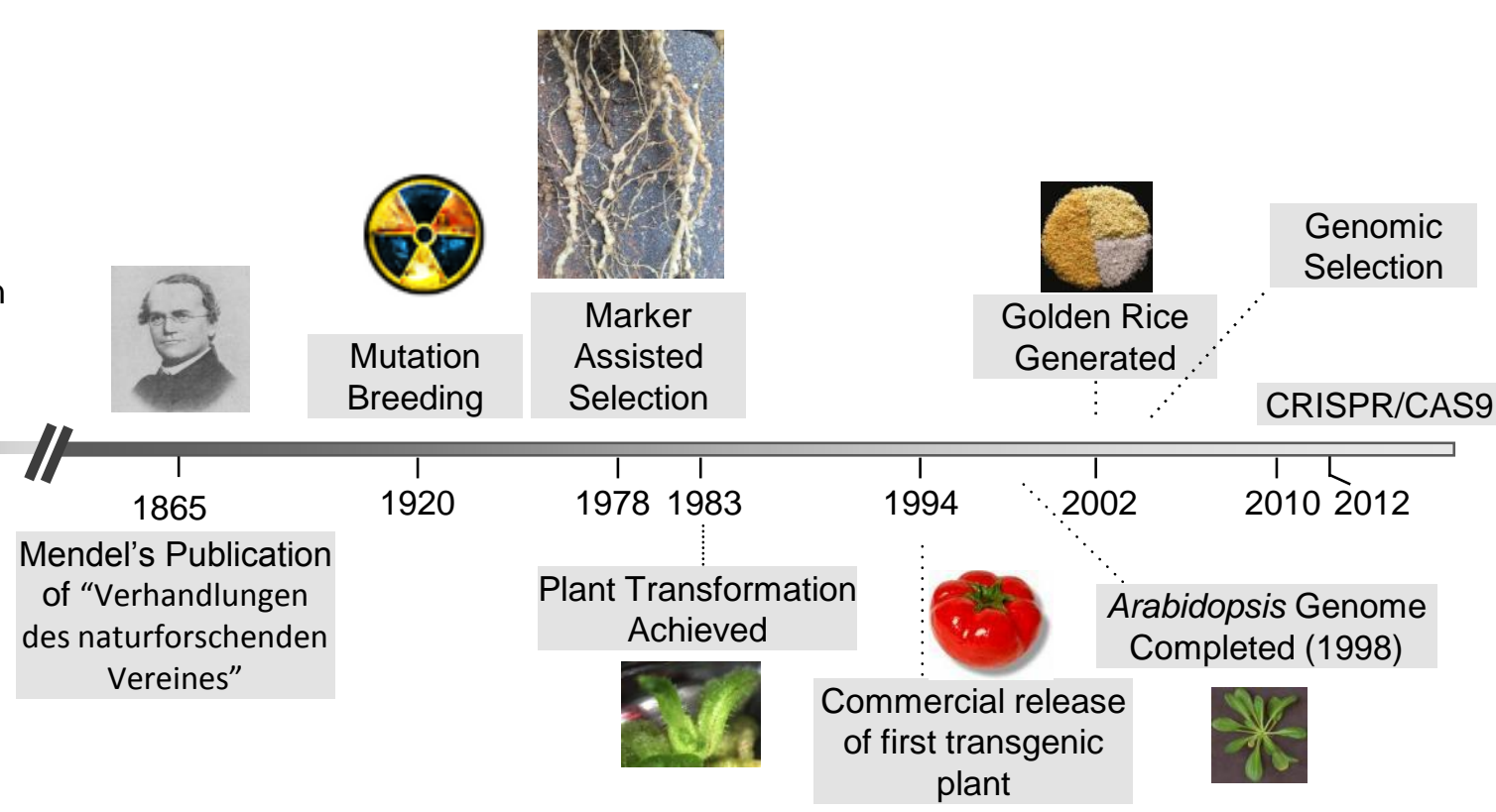




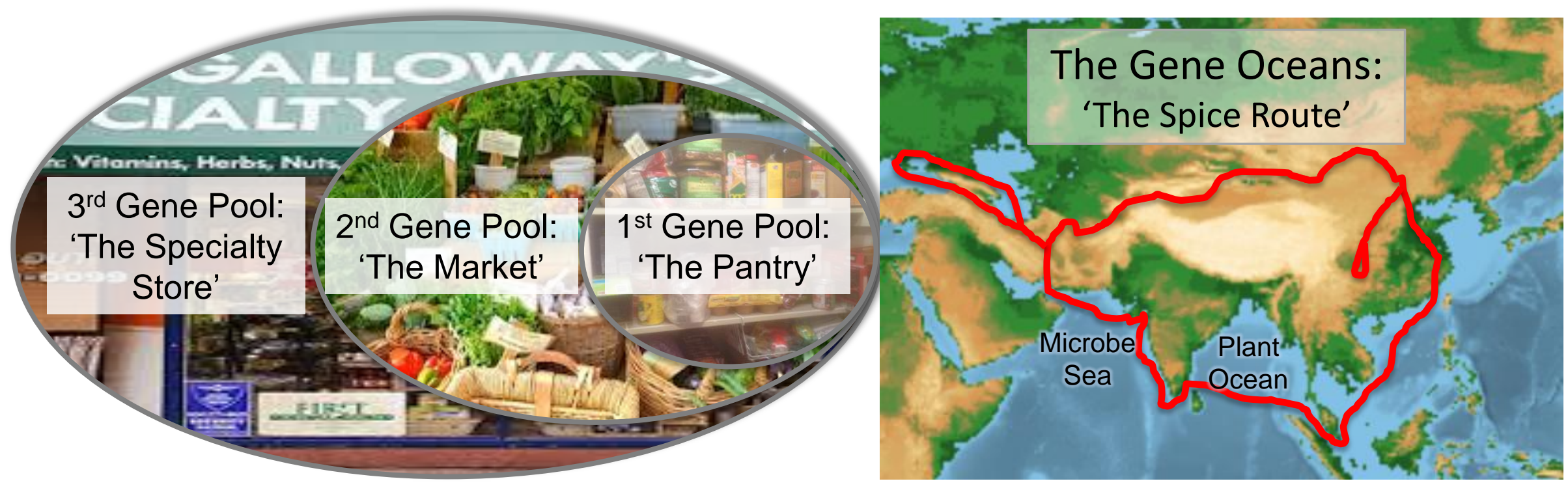

